\title{
Alzheimer's Disease and Peripheral Infections: The Possible Contribution from Periodontal Infections, Model and Hypothesis
}

\author{
Angela R. Kamer ${ }^{a, *}$, Ananda P. Dasanayake ${ }^{\mathrm{b}}$, Ronald G. Craig ${ }^{\mathrm{a}}$, Lidia Glodzik-Sobanska ${ }^{\mathrm{c}}$, \\ Miroslow Bry ${ }^{\mathrm{c}}$ and Mony J. de Leon ${ }^{\mathrm{c}, \mathrm{d}}$ \\ ${ }^{a}$ Department of Periodontics and Implant Dentistry and Basic Sciences, NYU College of Dentistry, New York, NY, \\ USA \\ ${ }^{\mathrm{b}}$ Department of Epidemiology, NYU College of Dentistry, New York, NY, USA \\ ${ }^{\mathrm{c}}$ Department of Psychiatry, Center for Brain Health, NYU School of Medicine, New York, NY 10016, USA \\ ${ }^{\mathrm{d}}$ Nathan Kline Institute, Orangeburg, NY, USA
}

\begin{abstract}
Alzheimer's disease (AD) affects approximately 4.5 million people in the U.S. and this number will increase as the population ages and the life-span increases. Therefore, of paramount importance is identifying mechanisms and factors that affect the risk of developing AD. The etiology and pathogenic mechanisms for AD have not been defined, although inflammation within the brain is thought to play a role. Consistent with this hypothesis, studies suggest that peripheral infections contribute to the inflammatory state of the central nervous system. Periodontitis is a prevalent, persistent peripheral infection associated with gram negative, anaerobic bacteria that are capable of exhibiting localized and systemic infections in the host. This review offers a hypothetical link between periodontitis and $\mathrm{AD}$ and will present possible mechanistic links between periodontitis related inflammation and $\mathrm{AD}$. It will review the pathogenesis of periodontitis and the mechanisms by which periodontal infections may affect the onset and progression of AD. Since periodontitis is a treatable condition, it may be a readily modifiable risk factor for $\mathrm{AD}$.
\end{abstract}

Keywords: Alzheimer's disease, cytokines, periodontal bacteria, periodontitis, peripheral infection

\section{INTRODUCTION}

Alzheimer's disease (AD) is one of the most common causes of dementia in elderly populations [12], afflicting approximately 4.5 million people in the United States. Although the prevalence and incidence vary among study populations, these rates increase signif-

*Corresponding author: Angela Ruth Kamer, DDS, MS, Ph.D., Assistant Professor, NYU College of Dentistry, Department of Periodontics and Implant Dentistry, 345 East 24th Street, New York, NY 10010, USA. Tel.: +1 212998 9868; Fax: +1 212995 4603; E-mail: ark5@nyu.edu. icantly with age [28]. It is projected in 50 years, as the population ages and the life-span increases, AD will afflict approximately 14 million people [94]. It is therefore clear that AD constitutes an increasing public health concern. However, the prevalence of AD will not change significantly unless new treatments emerge that can prevent, reverse, delay the onset or slow the progression of the disease. It is estimated that delaying the onset of $\mathrm{AD}$ by 5 years could result in $50 \%$ decrease in its prevalence in 50 years. Susceptibility to develop AD is dependent upon genetic and environmental factors [32]. While some AD risk factors are immutable others may be modifiable and therefore may 
constitute a means to significantly limit the prevalence of this disease in the future.

While the specific factors involved in the etiology and pathogenesis of $\mathrm{AD}$ are not well characterized, inflammation is thought to play a significant role. A central tenet of the inflammatory hypothesis is that peripheral processes alter brain inflammation. Studies have shown that peripheral infections can hasten the onset and progression of AD although the mechanisms are not well understood [41,83]. Periodontal disease (PD) is a common, chronic, peripheral infectious disease that has been linked to other systemic inflammatory conditions. The objective of this review is to present possible mechanistic links between PD and AD. It will offer evidence in support of a model explaining the initiation and maintenance of inflammation in $\mathrm{AD}$ and associated progressive $\mathrm{AD}$ related pathology. According to our model, periodontal bacteria induce pro-inflammatory cytokines and C-reactive protein (CRP) which stimulate glial cells to produce amyloid- $\beta$ 1-42 peptide (A $\beta 42)$ and hyperphosphorylated tau protein (P-Tau) which consequently induces production of more inflammatory molecules. Thus a vicious circle is established in which the inflammatory mediators play a double role by: a) activating pathways leading to neurodegeneration; and b) perpetuating a cascade of neuropathology. While there is evidence to support the elements of the proposed hypothetical model, to date there is no direct evidence implicating $\mathrm{PD}$ in pathogenesis of AD.

In addition, the unique features of PDs including chronicity, prevalence, association with Gram negative bacteria and their products such as LPS, induction of pro-inflammatory cytokines, and clinical ease of access, may provide a human model to investigate the role and the mechanisms through which peripheral infections contribute to the pathogenesis of AD.

\section{PATHOGENESIS OF ALZHEIMER'S DISEASE}

\section{Inflammation and pro-inflammatory cytokines}

The central tenet of the inflammatory hypothesis is the presence inflammation in the brain that becomes self perpetuating and induces neurodegeneration [40, 71,72]. Factors that initiate and maintain inflammation in $\mathrm{AD}$ are unknown but potential factors include $\mathrm{A} \beta 42$ found in senile plaques, P-Tau found in neurofibrillary tangles, or components of the degenerated neurons themselves $[2,75,76]$. These factors are able to stimu- late glial cells to produce pro-inflammatory cytokines such as tumor necrosis factor- $\alpha$ (TNF- $\alpha)$, interleukin$1 \beta$ (IL-1 $\beta$ ), interleukin-6 (IL-6) and inflammation associated factors such as CRP $[52,67,134]$ that not only perpetuate the inflammatory cycle but also are effectors in the pathway of neurodegeneration.

Evidence for a role of pro-inflammatory cytokines in $\mathrm{AD}$ comes from studies of clinical specimens and mechanistic-based in vitro studies. Imunocytochemistry data has shown that senile plaques immunoreact with antibodies against TNF- $\alpha$, IL- $1 \beta$, IL-6, CRP and complement proteins $[74,136]$ and that these plaques are associated with reactive astrocytes and activated microglial cells [2]. In vitro studies have shown that TNF$\alpha$, IL- $1 \beta$, IL- 6 can stimulate the synthesis of A $\beta 42$ and phosphorylation of tau protein $[37,75,76]$. In addition, $\mathrm{A} \beta 42$ and $\mathrm{P}-\mathrm{Tau}$ are capable of stimulating the production of TNF- $\alpha$, IL- $1 \beta$, IL- 6 by glial cells and A $\beta 42$ can activate the complement cascade that can activate and amplify pathways leading to neurodegeneration [37, 69].

In clinical studies, elevation of CRP (an acute phase protein synthesized mainly by the liver during systemic inflammation) and other pro-inflammatory markers were found to be predictive of AD. High levels of CRP were found to increase the risk of $\mathrm{AD}$ up to 3 fold [27] and cognitive decline in various populations $[58,124,125,133]$. A nested case-control study of 1,050 subjects derived from the Honolulu-Asia Aging Study showed that higher levels of CRP increased the risk of developing $\mathrm{AD}$ in the following 25 years [107].

The literature investigating a limited number of proinflammatory cytokines as predictors of $\mathrm{AD}$ is not as clear. Elevated IL-6 moderately increased the risk of AD even after adjusting for age, gender, smoking, body mass index, medications and diabetes and correlated with disease severity [48]. Elevated IL- $1 \beta$ and TNF- $\alpha$ increased the risk of cognitive decline in $\mathrm{AD}$ and elderly subjects [41] while subjects with increased production of IL- $1 \beta$ and TNF- $\alpha$ by peripheral blood mononuclear cells were at increased risk of developing AD [123]. Children with Down syndrome have been reported to have a higher risk of developing $\mathrm{AD}$ and have higher plasma levels of IL-6, CRP and cell adhesion molecules compared to control children [62] suggesting a role of pro-inflammatory molecules in the development of AD. However, other studies, such as the Longitudinal Aging Study Amsterdam, did not find an association between serum IL-6, CRP and cognitive decline but did find an association with $\alpha(1)$-antichymotrypsin (ACT), an acute-phase protein [23]. The discrepancy in findings 
is not surprising. In general, the measurement of proinflammatory cytokines at a single time point may not be reflective of levels over time or may not reflect levels when challenged by infection. Often IL- 6, IL- $1 \beta$ and TNF- $\alpha$ are operative in several effector pathways and their affect may be due to additive/synergistic roles or by contribution from other factors. In addition, most of the cited studies investigated only selected cytokines, therefore reflecting a limited aspect of inflammation. Support for this later hypothesis comes from a recently published study in Nature that showed that a group of 18 molecules including several inflammatory molecules found in plasma could be used to predict the progression of mild cognitive impairment to AD [99].

Additional support for the "inflammatory hypothesis" comes from studies that suggest that antiinflammatory drugs may slow the onset of AD. The Baltimore and Rotterdam studies showed that a history of anti-inflammatory drug use of at least 2 years duration reduced the risk of $\mathrm{AD}$, suggesting that a reduction in inflammation protects against the onset of dementia $[44,120]$. In addition, a meta-analysis supported the beneficial effect of anti-inflammatory drugs in decreasing the risk of AD [70]. These studies taken together suggest that peripheral inflammation may play a significant role in the pathogenesis of AD. However, some studies have not found anti-inflammatory drugs to decrease risk for $\mathrm{AD}$ and have offered alternate explanations and they included dosage and type of the drug, APOE status [121,122] and biological effect. For example, ibuprofen and indomethacin has been reported to lower the $\mathrm{A} \beta 42$ (important role in the formation of amyloid plaques) [131] while celecoxib increased its production [128]. These studies do not refute the "inflammatory hypothesis" but suggest that more studies on the role and mechanisms of inflammation and anti-inflammatory drugs in the pathogenesis of $\mathrm{AD}$ are needed.

Cytokine gene polymorphisms and their association with AD have been studied. In particular, the presence of a composite genotype characterized by IL- $1 \alpha-889$ and IL- $1 \beta+3953$ polymorphisms conferred an almost 11-fold increased risk of developing AD [85], presumably due to increased IL- 1 levels. It should be noted that the presence of IL- $1 \alpha-889$ and IL- $1 \beta+3953$ polymorphisms has also been associated with a 7-fold increased risk of PD in non-smokers [55]. These studies suggest that, although AD and PD are separate diseases with unique pathogenic bases, their onset, severity and progression may be influenced by common risk factors. Offenbacher [87] in the dental literature and McGeer in the neurological literature [73] suggest that an inflammatory trait may exist which is characterized by an amplified response to an injurious stimulus [87]. This inflammatory trait may increase susceptibility and modify the expression of a disease with an inflammatory etiology.

Relatively large pro-inflammatory molecules such as TNF- $\alpha$, IL- $1 \beta$ and IL- 6 have limited access to the brain. Nonetheless, evidence exists that these molecules reach the brain by at least two mechanisms: a) systemic circulation and b) neural pathways (reviewed by Banks and Quan and Banks) [5,97]. Cytokines within systemic circulation may affect blood-brain barrier (BBB) permeability, may bind to areas of the brain that lack a BBB such as circumventricular organs [10], may cross through fenestrated capillaries of the BBB or may use cytokine-specific transporters [11]. Cytokines may also activate brain endothelial and perivascular cells [106] to induce production of other signaling molecules such as nitric oxide (NO), prostanoids or other cytokines that in turn stimulate glial cells [54, $63,97]$. Thus, peripheral molecules may increase the existing brain cytokine pool concentration by addition or by glial stimulation. If the glial cells are already primed (activated), as is likely to occur with increasing age or display an hyper-inflammatory phenotype, stimulation will result in amplified responses with considerable inflammatory molecule production $[18,36$, 93]. Peripheral cytokines may also impact the brain pro-inflammatory cytokine pool through neuronal pathways [21]. This mechanism implies that peripheral cytokines stimulate afferent fibers of peripheral nerves leading to increased brain cytokines. The significance of this mechanism is that signaling cytokines may be only needed to be elevated locally and not systemically [82]. Although, this mechanism has been mostly described for the vagus nerve [130], nerves enervating the oral cavity such as the glossopharyngeal and trigeminal nerves have also been proposed [103].

Bacterial products may also increase brain cytokine levels. Lipopolysaccharide (LPS), a component of Gram negative cell walls and a potent pathogen-associated molecular pattern for the innate immune response, is capable of increasing peripheral cytokine concentrations and up-regulating CD14 receptors throughout the brain [100]. There, CD14 can be activated by existing $\mathrm{A} \beta$ protein or LPS derived from invasive bacteria increasing further the brain cytokines. Consistent with this mechanism, peripheral administration of LPS into APPswe transgenic mice increased the accumulation of amyloid- $\beta$ protein precursor $(\mathrm{A} \beta \mathrm{PP})$ 
and $\mathrm{A} \beta$ [111]. Another possibility is that peripheral LPS may increase the permeability of the BBB [14] allowing the passage of at least some molecules, cells and possible bacteria into the brain.

\section{Peripheral infection and Alzheimer's disease}

Linked with the inflammatory hypothesis is the pathogen hypothesis that suggests some pathogens act as triggers or co-factors in the etiology and pathogenesis of AD [45]. This hypothesis is supported by several preliminary clinical studies. A prospective study showed impaired cognitive function in AD patients for at least two months after the resolution of a systemic infection [41]. In addition, peripheral infections were reported to increase the risk of delirium in patients with $\mathrm{AD}[60]$ and in a twin study, a history of past severe peripheral infections accelerated the onset of $\mathrm{AD}$ [83].

Several bacterial species have been implicated in the pathogenesis of AD including Chlamydia pneumoniae, Helicobacter pylori and spirochetes, although conflicting evidence exists for some bacteria. One postmortem study reported $C$. pneumoniae present in 17 of 19 samples from individuals with $\mathrm{AD}$, but only present in 1 of 18 samples from non-AD, age matched controls [4]. However, another study did not replicate this finding [35]. Higher serum IgG antibody against H. pylori has been reported in AD subjects compared to controls [56]. Spirochetes, identified by dark field microscopy, were reported present in blood, CSF and brain samples from 14 AD cases but were absent in 13 controls lacking symptoms of AD [78,79]. Although not all species of spirochetes were characterized, at least some of the spirochetes were Borrelia burgdorferi [80]. These finding were consistent with MacDonald's findings that cultivated $B$. burgdorferi from brain samples from AD patients [68]. In addition, $B$. burgdorferi specific antigens were co-localized with A $\beta$ deposits and glial and neuronal cells exposed to $B$. burgdorferi were able to produce amyloid beta precursor protein and hyperphosphorylated tau proteins [81], suggesting that $B$. burgdorferi is able to induce AD specific pathology. Of interest, spirochetes from the oral cavity have been reported by Riviere in brain samples from AD patients were using molecular and immunological methods [101]. These results suggest, as did Miklossy's results that spirochetes within brain tissue may originate from diverse areas including the oral cavity [78].

\section{PERIODONTAL DISEASE}

PDs are a heterogeneous group of diseases that affect the supporting structures of the teeth. The infectious forms of PD are caused by bacteria in the dental plaque and the most common are dental plaque-induced gingival diseases or gingivitis, chronic and aggressive periodontitis. Gingivitis is an inflammatory, reversible condition limited to the gingiva characterized by erythema, edema, bleeding and gingival enlargement. Gingivitis is a very common occurrence in both children and adults ranging from $30 \%$ to $90 \%$ in children and 40 $50 \%$ in adults [46]. Chronic and aggressive periodontitis (in this review they will be referred as periodontitis) are destructive and irreversible forms of PD in which the inflammation extends from the gingiva to the tooth's attachment apparatus including the bone. Clinically, periodontitis presents similar features to that of gingivitis but in addition, there is soft connective tissue and often bone loss creating deep, ulcerated pockets (groove between the tooth and its supporting tissue) around the teeth that ultimately leads to tooth loss. It was estimated that in subjects with periodontitis the surface of epithelium lining the pockets ranged from 8 to $20 \mathrm{~cm}^{2}$ suggesting large areas of possible concealed, ulcerated surfaces [42].Approximately $35 \%$ of the dentate U.S. adults between 30 and 90 years of age have PD. Increasing with age, it affects approximately $50 \%$ people over the age of 55 [3].

\section{Pathogenesis of periodontal disease}

The health of periodontal tissue is maintained by a balance between bacteria populating the dental biofilm and host immune response [55]. In gingivitis the host innate and adaptive immune system are able to control the bacterial infection. In periodontitis however, the balance between bacteria and host response is disturbed, resulting in an uncontrolled inflammation characterized by the production of high levels of inflammatory mediators such as IL-1, IL-6, IL-17 and TNF- $\alpha$, and low levels of anti-inflammatory molecules such as IL-10 [9,57]. These molecules act in concert to amplify the inflammatory reaction and activate the effector mechanisms responsible for tissue destruction in PDs (Fig. 1). Metalloproteinases are also activated and collagen synthesis is inhibited. Cells including $\mathrm{T}$ and $\mathrm{B}$ cells are stimulated to express receptor activator of nuclear factor $\kappa \mathrm{B}$ ligand (RANKL) [49] a significant factor in osteoclast activation. RANKL binds to receptor activator of nuclear factor $\kappa \mathrm{B}$ (RANK) found on osteo- 


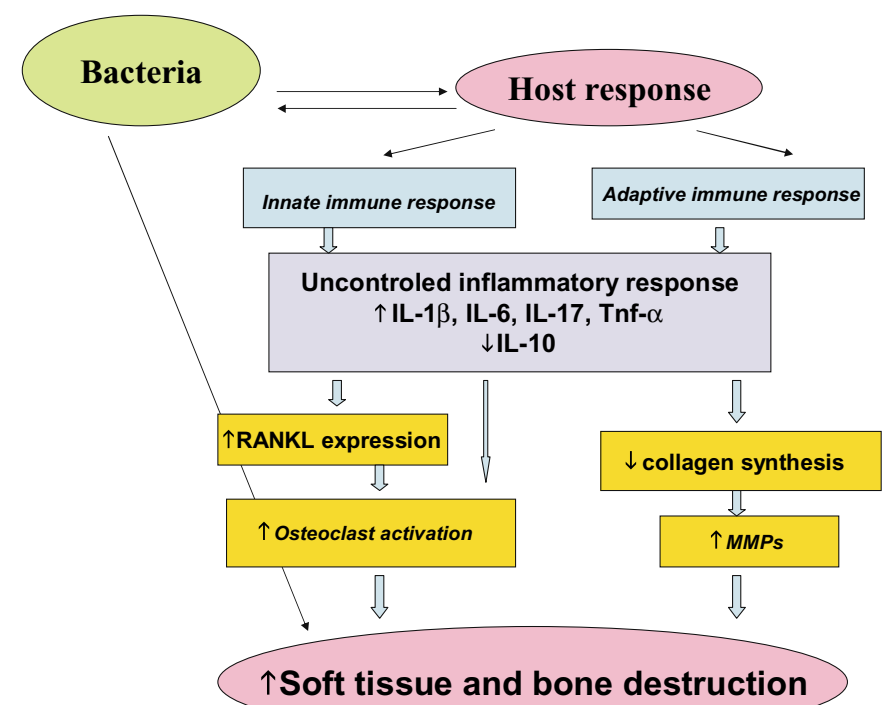

Fig. 1. Pathogenesis of periodontitis. In disease susceptible individuals, the balance between periodontal bacteria and host response is disturbed and an innate and adaptive immune system is activated with local and systemic release of inflammatory mediators such as Il1, 6 and TNF. Activation of the effector's mechanisms (osteoclast activation, decreased collagen synthesis, increased expression and activity of metalloproteinases) leads to significant tissue destruction.

clasts and signals them to proliferate, differentiate and become activated. Activated osteoclasts then resorb the alveolar bone that ultimately leads to tooth loss. These findings show that inflammatory reaction mounted by the host impacts the occurrence and the expression of PD.

\section{Periodontal bacteria}

PD is a chronic, multibacterial infection. Periodontal bacteria exist within a complex ecosystem called dental biofilm forming on the tooth surface. In addition to microorganisms and their components (endotoxin, virulence factors), dental biofilm is composed of other proteinecious and nonproteinecious materials providing a system in which periodontal bacteria growth is favored and protected from the host defense mechanisms or antibacterial drugs [117].

Bacterial species populating the dental biofilm are numerous (aproximatly 400 species) [91]. Some of the bacterial species such as Streptococus, Actinomyces, Capnocytophaga andVeillonella are early colonizers of the tooth surface, mainly gram positive and associate with gingival health [116]. In gingivitis, $50 \%$ of bacteria are still gram positive but gram negative bacteria belonging to Treponema and Fusobacterium nucleatum species [115] are increasing in number. In periodontitis, approximately $85 \%$ of bacteria are gram negative and among them, Aggregatibacter actinomycetemcomitans (A. actinomycetemcomitans) (formerly known as Actinobacillus actinomycetemcomitans), Tannerella forsythensis (T. forsythensis) (formerly known as Bacteroides forsythu), Porphyromonas gingivalis ( $P$. gingivalis), Treponema denticola ( $T$. denticola), Campylobacter rectus (C. rectus) and Fusobacterium nucleatum (F. nucleatum) are considered important periodontal pathogens [117]. In the periodontal pocket, periodontophatic bacteria occurs close to the soft tissue wall [38] favoring the invasion of epithelial and connective tissue [104] by some bacteria.

In addition to periodontal bacteria, there is evidence to suggest a role for human herpesvirus species particularly Epstein-Barr virus (EBV) and type 1 human cytomegalovirus (HCMV) in the pathogenesis of periodontitis [114]. These findings however are relatively new and more research is needed to investigate their contribution to periodontitis and systemic diseases [95].

\section{Host response in periodontal disease}

Inflammatory chemokines such as IL-8, Monocyte chemotactic protein-1 (MCP-1) and cytokines such as IL-1 $\beta$, IL-6, IL-17 and TNF- $\alpha$ have a prominent role in the pathogenesis of PD $[61,112]$. They are elevated within the diseased periodontal tissues, gingival crevicular fluid (GCF) and in plasma suggesting their chronic production. 
Local host response in periodontitis: GCF is an exudate expressed in the gingival sulcus and may be considered a "window to PD" [129]. In addition to molecules derived from serum, GCF is also composed of substances derived from interstitial tissue and cells [129]. Up to $94 \%$ of inflamed periodontal sites have elevated levels of IL- $1 \beta$ in the GCF collected from those sites [135]. Progressive disease has higher levels of IL$1 \beta$ in their GCF than nonprogressive disease $[15,31]$ and treatment of PD decreases IL- $1 \beta$ values [26]. Within subjects with periodontitis, healthy sites had higher values of IL- $1 \beta$ than healthy sites from subjects with mild periodontitis [26] suggesting that GCF production of inflammatory mediators may be subject specific. This later hypothesis is supported by studies showing that periodontal subjects with specific polymorphisms in the IL- 1 gene produce 2.5 more IL- $1 \beta$ in shallow pockets than subjects having periodontitis but without these polymorphisms [25]. IL-6, TNF- $\alpha$, IL-17, IL-8 and MCP-1 have also been found to be increased in GCF of patients with PD [47,59].

Systemic host response in periodontitis: $\mathrm{PD}$ is a localized disease but when present in severe forms may induce a systemic inflammation demonstrated by the elevation of inflammatory markers in the blood such as CRP and various cytokines. CRP is an acutephase response protein that is known to increase up to 1000 folds in acute inflammatory diseases [110]. CRP also increases in chronic inflammatory conditions. In rheumatoid arthritis, CRP values may well exceed $100 \mathrm{mg} / \mathrm{L}$ while in chronic protracted conditions such as those caused by $H$. pylori or $C$. pneumoniae may be only slightly to moderate elevated (median 0.3$7.99 \mathrm{mg} / \mathrm{L}$ ) [77]. However, the attention on CRP levels stems from its predictive value of cardiovascular diseases. The US Centers for Disease Control and Prevention and the American Heart Association [92] defined subjects at average risk if CRP is $1.0-3.0 \mathrm{mg} / \mathrm{L}$, and high risk if CRP is $>3.0 \mathrm{mg} / \mathrm{L}$. Subjects with periodontal disease have been found to have elevated CRP values compared to healthy controls $[16,24,86]$ particularly when they had severe disease [86] with means exceeding 3mg/L [65]. For example, data derived from National Health and Nutrition Examination Survey III showed that subjects with extensive PD were more likely to have high levels of CRP [ $>10 \mathrm{mg} / \mathrm{L}]$ than subjects without PD [113]. In fact, $12.5 \%$ of subjects with extensive PD had high CRP levels compared to $6 \%$ subjects without PD. These high levels of CRP denote a significant inflammatory state and are in the range that is considered a risk for cardiovascular dis- ease [127]. Treatment of PD resulted in the decrease of CRP levels that was more likely in subjects that were responsive to periodontal treatment [20] supporting the notion that the elevated CRP was PD related. The presence of systemic IL- $1 \beta$, IL- 6 and TNF- $\alpha$ was also examined although these studies are limited. However, they suggest that higher proportion of subjects with periodontitis have detectable plasma IL-6 compared to controls [64]. Plasma IL-6 and TNF- $\alpha$ may decrease following periodontal treatment suggesting that these markers reflect periodontal infections [19]. However, plasma level of IL-1 and TNF- $\alpha$ appear to depend on the severity of injury [6] and therefore their levels may be more difficult to detect if PD is not severe or extensive enough.

$P D$ as a risk factor for other systemic diseases: In addition to periodontal pathology, periodontopatic bacteria are also capable of causing systemic pathology. Examples of these pathologies are endocarditis [8], brain and lung abscesses and pulmonary disease [137]. In the first instances periodontal bacteria gained access to the systemic circulation and metastasized at distant sites, however, in pulmonary disease periodontal bacteria reached the pulmonary tree by aspiration [105]. Other systemic diseases associated with PDs are diabetes, low weight birth, cardiovascular and renal diseases $[17,22,84,126]$. In these instances two mechanisms of action may be involved: 1) direct bacterial/bacterial products action at the site of pathology through bacteriemia, endotoxemia and virulence factor release in the circulation and 2) host response mechanisms to periodontal bacteria implicating the inflammatory mediators that are released systemically.

Bacteriemia derived from the oral cavity is a frequent occurrence during treatment or even examination and depends on the procedures performed and the presence of gingivitis/periodontitis or severity of periodontitis [89]. Even daily procedures such as flossing, brushing and mastication may induce bacteriemia with a comparable prevalence to the one induced by dental procedures [66] and the frequent nature of these procedures may lead to significant bacterial exposures [102]. Metastasizing at distant sites periodontal bacteria are capable of inducing pathology. For example, A. actinomycetemcomitans, $P$. gingivalis and $T$. denticola were recovered in atherosclerotic plaques $[39,90]$ and $P$. Gingivalis induced the expression of adhesion molecules and proinflammatory cytokines in aortic tissue and accelerated atherosclerosis in an animal model (apolipoprotein E-deficient mice) [34]. In another animal model (BALB/C mice), 
infection with $C$. rectus induced decreased expression of Insulin Growth Factor 2 (IGF2) mRNA by epigenetic modification of the Igf2 gene [13] and induced placental structural changes. These studies provide evidence for the diversity of molecular effects that periodontal bacteria are capable of inducing and possible mechanisms of actions for periodontal bacteria.

Endotoxemia may occur upon professional and nonprofessional dental manipulations and may be accompanied by elevation in TNF- $\alpha$, IL-6, CRP $[19,43]$ and possible mild fever [98] suggesting an association with a systemic acute phase response.

\section{ASSOCIATION BETWEEN PERIODONTAL DISEASE AND PROGRESSION OF ALZHEIMER'S DISEASE}

The mechanisms involved in the pathogenesis of $\mathrm{AD}$ are not known. However, inflammation is believed to play a significant role [1], and as such, processes capable of increasing the brain inflammatory state may contribute to the progression of $\mathrm{AD}$. PD is a chronic infectious disease resulting in years of significant bacterial and inflammatory local and systemic exposure. We propose the hypothesis PD may enhance the inflammation in the brain and contributes to the progression of AD (Fig. 2). We propose that two mechanisms may be involved in the $\mathrm{PD}$-induced progression of $\mathrm{AD}$ : 1) inflammatory and 2) bacterial mechanisms. The first mechanism implies that PD-derived inflammatory molecules increase brain inflammation. As described in the previous paragraph, the interaction between periodontopathic bacteria and host response results in locally increased production of inflammatory molecules including IL- $1 \beta$, IL-6, IL8, TNF- $\alpha$, and CRP. In severe or extensive $\mathrm{PD}$, these proinflammatory molecules may also induce systemic inflammation and therefore may access the brain via systemic circulation. Proinflammatory molecules derived locally from periodontal tissue may also stimulate trigeminal nerve fibers, leading to increased brain cytokines [103]. These cytokines may act on the already primed glial cells resulting in an amplified reaction and possible progression of $\mathrm{AD}$. A test of this hypothesis would entail examining whether PD affects the progression of AD manifested clinically as earlier onset or as more severe disease.

The second mechanism by which PD could contribute to brain inflammation is through bacteria and/or bacterial products. Several bacteria including oral ones are hypothesized to be implicated [78] (this issue) in the pathogenesis of AD. Among periodontal bacteria, species such as A. actinomycetemcomitans, $P$. gingivalis, $T$. denticola and $F$. nucleatum are capable of invading the brain, changing the cytokine milieu and possibly contributing to existing pathological mechanisms. For example, Treponema species including T. denticola were detected in 14/16 AD and 4/18 non-AD brains. In addition, $\mathrm{AD}$ specimens also had more Treponema species than controls [101]. In an animal model of oral infections T. denticola was detected postmortem in the brain [30]. These findings are not surprising since $T$. denticola is from the same class as Treponema pallidum which is also known to invade the brain, induce chronic inflammation, cortical atrophy and amyloid deposition in subjects with syphilis. Reports of brain abscess in which oral bacteria such as A. actinomycetemcomitans, $F$. nucleatum and possibly $P$. gingivalis are implicated attest to their capabilities to invade the brain and induce pathology.

Once in the brain, periodontal bacteria that are rich in LPS or their products are capable of stimulating cytokine production. For example, heat-killed P. gingivalis administered through a subcutaneous chamber to mice with induced experimental autoimmune encephalomyelitis aggravated the disease compared to controls [109] possibly through an inflammatory mechanism as $P$. gingivalis -derived LPS stimulated NO and prostaglandin E2 (PGE2) in rat glial cells [108,109]. Since $P$. gingivalis LPS stimulates the human cells through CD14 and toll-like receptors (TLR-2 and 4), it has been suggested that perhaps brain-induced inflammation induced by $P$. gingivalis -derived LPS may be mediated by these receptors [50]. Additional evidence comes from Offenbacher's studies [88]. In a subcutaneous chamber infection model, challenge of embryonic mice with $C$. rectus resulted in hippocampal morphological changes in pups including cytoplasmic vacuoles and cellular debris suggestive of cellular damage. Molecularly, the fetal brain of challenged embryos had about twice more TNF- $\alpha$ and IFN- $\gamma$ m-RNA compared to nonchallenged embryos [88].

The mechanism by which periodontal bacteria have access to the brain is not known. However, the mechanisms described for other bacteria such as access via systemic circulation is possible. Bacteriemia of oral origin occurs quite frequently during dental and nondental manipulations. Other ways bacteria may reach the brain is via peripheral nerves. Riviere's studies showed that spirochete species were detected in the trigeminal ganglia and pons suggesting the ability of oral spirochetes to invade CNS via peripheral 


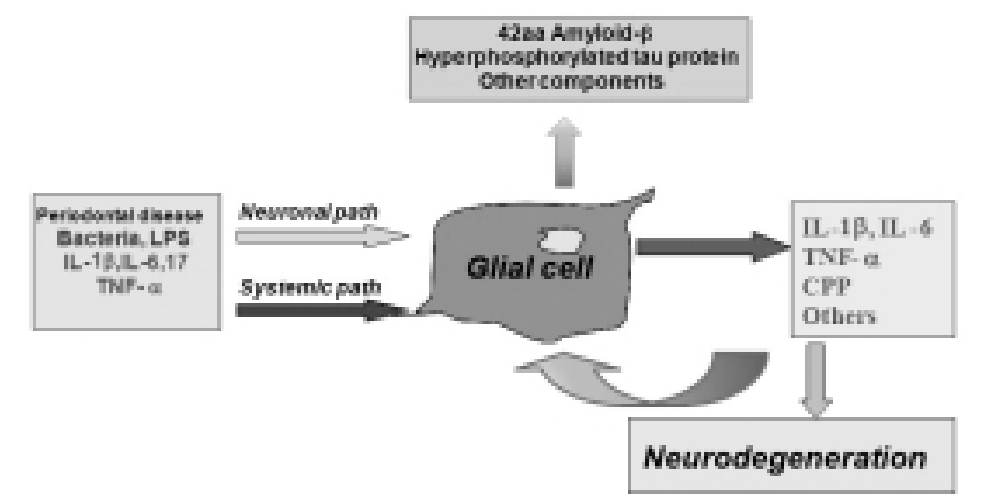

Fig. 2. Model for PD-induced progression of AD. The central theme of AD pathogenesis is the inflammation as illustrated by the activated glial cell that produces high levels of inflammatory molecules such as Il-1 $\beta$, Il-6, TNF- $\alpha$ and CRP. PD may affect the initiation, progression of AD by directly (bacterial invasion) or indirectly (LPS, cytokines, CRP) increase brain inflammation via neuronal or systemic pathways. These molecules would further amplify the inflammatory signal by activating the already primed glial cells and increase production of molecules such as $\mathrm{A} \beta$ peptide, hyperphosphorylated tau proteins and ultimately activate pathways leading to degeneration.

nerves [101]. However, the mere presence of periodontal bacteria in the systemic circulation or in peripheral nerve fibers territory does not imply access to the brain. Perhaps additional cofactors are needed such as age, the presence of inflammatory cytokines or other infections [14,29].

Direct clinical evidence for an association between $\mathrm{PD}$ and $\mathrm{AD}$ is lacking. Tooth loss is a frequent occurrence and may be due to multiple factors including PD. Several studies with different designs showed that tooth loss was associated with dementia and AD [53]. For example analysis of data coming from "2000 Health Survey for England" showed that loss of teeth was associated with cognitive impairment [119]. Similar results were obtained by Kim that studied the dental health in a Korean population [51]. A Swedish study showed in monozygotic twins, for whom genetic factors were controlled for there was a strong association between tooth loss and the presence of AD. In fact, the twin having tooth loss was 5.5 times more likely to develop AD later in life compared to his/her sibling [33]. A recent prospective follow-up study, examined the oral health of participants in the "Nun Study" a longitudinal study of aging and AD in Milwaukee, USA and reported that lower number of teeth increased the risk of dementia with a OR $=6.4$ [118]. This increase however, occurred only in noncarries of APOE $4 \varepsilon$ allele and not in the carriers. This result is interesting since our preliminary data (unpublished data) found that among 17 noncarrier subjects, 11 of them tested positive for at least one type of IgG antibody to periodontal bacteria examined (A.actinomycetemcomitans, T.forsythensis and $P$. gingivalis). By comparison, among 17 carriers, 7 of them tested positive. Antibodies to periodontal bacte- ria represent an index of periodontal infection and although not statisticaly significant ( $p=0.169,2$-sided $\chi^{2}$ ) these results are consistent with the "Nun study". The authors of the "Nun study" speculated that since APOE $4 \varepsilon$ is a strong risk factor for AD may significantly modify the tooth loss-dementia relationships. However, alternative explanations may exist. If antibody response to periodontal bacteria reflects the existence of periodontal disease $[7,96]$ then noncarriers of APOE $4 \varepsilon$ may be at an increased risk for periodontal disease. As Wozniak and Itzhaki proposed the APOE carrier status may positively or negatively influence the outcome of an infection [132]. And still another explanation is that perhaps noncarriers have a better protective adaptive immune response to periodontal bacteria than carriers. Powered studies concomitantly investigating the prevalence of periodontal disease, periodontal bacterial colonization and adaptive immune responses to these bacteria may answer these questions.

Stein [118] also investigated the association between bone loss around teeth, a PD characteristic and dementia and no association was found. However, as the authors pointed out, bone loss assessments on unstandardized radiographs are questionable. In addition, bone loss represents the history of PD with no accompanying knowledge of inflammatory or/and bacterial burden. Since PD contribution to AD pathogenesis may be through its inflammatory and bacterial burden, when studying PD as a predictor for AD, perhaps measures depicting inflammation and bacteria or their interaction may be more relevant.

Clinical studies consistently show an association between tooth loss and AD/dementia [118,119]. In addition to PD, caries (tooth decay) and endodontic com- 
plications are significant causes of tooth loss and the possibility that these oral infections may contribute to AD pathogenesis cannot be excluded.

\section{CONCLUSIONS}

AD prognosis has not changed significantly during the last decades largely due to the limited understanding of the mechanisms involved in disease initiation and its progression. Understanding the factors and the mechanisms involved in the initiation and progression to $\mathrm{AD}$ is of paramount importance. We propose that PD with significant bacterial and inflammatory burden may enhance the inflammation in the brain and contributes to the initiation/progression of AD. Although no direct evidence associates $\mathrm{PD}$ to $\mathrm{AD}$, indirect findings suggest this possibility. If this hypothesis is true, then several implications exist: a) the presence of PD may alert the patients to the risk of acquiring AD later in life; b) early treatment of PD may limit the severity of $\mathrm{AD}$ and its progression; and c) it will demonstrate that peripheral infections may play a significant role in the pathogenesis of AD. We propose the direct investigation of the relationships between $\mathrm{PD}$ and $\mathrm{AD}$ is warranted.

\section{ACKNOWLEDGMENTS}

The writing of this review was supported by a NYUSOM grant and NYUCD. Dr. Craig is a paid advisory board member or consultant for Novartis Pharmaceuticals, Matrixx Initiatives, and SunStar Butler Corporation.

\section{References}

[1] H. Akiyama, T. Arai, H. Kondo, E. Tanno, C. Haga and K. Ikeda, Cell mediators of inflammation in the Alzheimer disease brain, Alzheimer Dis Assoc Disord 14(Suppl 1) (2000), S47-S53.

[2] H. Akiyama, S. Barger, S. Barnum, B. Bradt, J. Bauer, G.M. Cole, N.R. Cooper, P. Eikelenboom, M. Emmerling, B.L. Fiebich, C.E. Finch, S. Frautschy, W.S. Griffin, H. Hampel, M. Hull, G. Landreth, L. Lue, R. Mrak, I.R. Mackenzie, P.L. McGeer, M.K. O'Banion, J. Pachter, G. Pasinetti, C. Plata-Salaman, J. Rogers, R. Rydel, Y. Shen, W. Streit, R. Strohmeyer, I. Tooyoma, F.L. Van Muiswinkel, R. Veerhuis, D. Walker, S. Webster, B. Wegrzyniak, G. Wenk and T. Wyss-Coray, Inflammation and Alzheimer's disease, Neurobiol Aging 21 (2000), 383-421.

[3] J.M. Albandar, Periodontal diseases in North America, Periodontol 200029 (2002), 31-69.
[4] B.J. Balin, H.C. Gerard, E.J. Arking, D.M. Appelt, P.J. Branigan, J.T. Abrams, J.A. Whittum-Hudson and A.P. Hudson, Identification and localization of Chlamydia pneumoniae in the Alzheimer's brain, Med Microbiol Immunol (Berl) 187 (1998), 23-42.

[5] W.A. Banks, Blood-brain barrier transport of cytokines: a mechanism for neuropathology, Curr Pharm Des 11 (2005), 973-984.

[6] T.T. Bauer, C. Monton, A. Torres, H. Cabello, X. Fillela, A. Maldonado, J.M. Nicolas and E. Zavala, Comparison of systemic cytokine levels in patients with acute respiratory distress syndrome, severe pneumonia, and controls, Thorax 55 (2000), 46-52.

[7] J.D. Beck and S. Offenbacher, Systemic effects of periodontitis: epidemiology of periodontal disease and cardiovascular disease, J Periodontol 76 (2005), 2089-2100.

[8] E.F. Berbari, F.R. Cockerill 3rd and J.M. Steckelberg, Infective endocarditis due to unusual or fastidious microorganisms, Mayo Clin Proc 72 (1997), 532-542.

[9] T. Berglundh and M. Donati, Aspects of adaptive host response in periodontitis, J Clin Periodontol 32(Suppl 6) (2005), 87-107.

[10] C.M. Blatteis, The afferent signalling of fever, J Physiol 526(Pt 3) (2000), 470.

[11] C.M. Blatteis, E. Sehic and S. Li, Pyrogen sensing and signaling: old views and new concepts, Clin Infect Dis 31(Suppl 5) (2000), S168-177.

[12] K. Blennow, M.J. de Leon and H. Zetterberg, Alzheimer's disease, Lancet 368 (2006), 387-403.

[13] Y.A. Bobetsis, S.P. Barros, D.M. Lin, J.R. Weidman, D.C. Dolinoy, R.L. Jirtle, K.A. Boggess, J.D. Beck and S. Offenbacher, Bacterial infection promotes DNA hypermethylation, J Dent Res 86 (2007), 169-174.

[14] M. Bohatschek, A. Werner and G. Raivich, Systemic LPS injection leads to granulocyte influx into normal and injured brain: effects of ICAM-1 deficiency, Exp Neurol 172 (2001), $137-152$.

[15] C.M. Champagne, W. Buchanan, M.S. Reddy, J.S. Preisser, J.D. Beck and S. Offenbacher, Potential for gingival crevice fluid measures as predictors of risk for periodontal diseases, Periodontol 200031 (2003), 167-180.

[16] R.G. Craig, J.K. Yip, M.K. So, R.J. Boylan, S.S. Socransky and A.D. Haffajee, Relationship of destructive periodontal disease to the acute-phase response, J Periodontol 74 (2003), 1007-1016.

[17] R.G. Craig, P. Kotanko, A.R. Kamer and N.W. Levin, Periodontal diseases - a modifiable source of systemic inflammation for the end-stage renal disease patient on haemodialysis therapy?, Nephrol Dial Transplant 22 (2007), 312-315.

[18] C. Cunningham, D.C. Wilcockson, S. Campion, K. Lunnon and V.H. Perry, Central and systemic endotoxin challenges exacerbate the local inflammatory response and increase neuronal death during chronic neurodegeneration, J Neurosci 25 (2005), 9275-9284.

[19] F. D’Aiuto, M. Parkar, G. Andreou, J. Suvan, P.M. Brett, D. Ready and M.S. Tonetti, Periodontitis and systemic inflammation: control of the local infection is associated with a reduction in serum inflammatory markers, $J$ Dent Res $\mathbf{8 3}$ (2004), 156-160.

[20] F. D'Aiuto, L. Nibali, M. Parkar, J. Suvan and M.S. Tonetti, Short-term effects of intensive periodontal therapy on serum inflammatory markers and cholesterol, J Dent Res 84 (2005), 269-273. 
[21] R. Dantzer, J.P. Konsman, R.M. Bluthe and K.W. Kelley, Neural and humoral pathways of communication from the immune system to the brain: parallel or convergent?, Auton Neurosci 85 (2000), 60-65.

[22] A.P. Dasanayake, D. Boyd, P.N. Madianos, S. Offenbacher and E. Hills, The association between Porphyromonas gingivalis-specific maternal serum IgG and low birth weight, J Periodontol 72 (2001), 1491-1497.

[23] M.G. Dik, C. Jonker, C.E. Hack, J.H. Smit, H.C. Comijs and P. Eikelenboom, Serum inflammatory proteins and cognitive decline in older persons, Neurology 64 (2005), 1371-1377.

[24] J.L. Ebersole, R.L. Machen, M.J. Steffen and D.E. Willmann, Systemic acute-phase reactants, C-reactive protein and haptoglobin, in adult periodontitis, Clin Exp Immunol 107 (1997), 347-352.

[25] S.P. Engebretson, I.B. Lamster, M. Herrera-Abreu, R.S. Celenti, J.M. Timms, A.G. Chaudhary, F.S. di Giovine and K.S. Kornman, The influence of interleukin gene polymorphism on expression of interleukin-1beta and tumor necrosis factoralpha in periodontal tissue and gingival crevicular fluid, $J$ Periodontol 70 (1999), 567-573.

[26] S.P. Engebretson, J.T. Grbic, R. Singer and I.B. Lamster, GCF IL-1beta profiles in periodontal disease, J Clin Periodontol 29 (2002), 48-53.

[27] M.J. Engelhart, M.I. Geerlings, J. Meijer, A. Kiliaan, A. Ruitenberg, J.C. van Swieten, T. Stijnen, A. Hofman, J.C. Witteman and M.M. Breteler, Inflammatory proteins in plasma and the risk of dementia: the rotterdam study, Arch Neurol 61 (2004), 668-672.

[28] D.A. Evans, H.H. Funkenstein, M.S. Albert, P.A. Scherr, N.R. Cook, M.J. Chown, L.E. Hebert, C.H. Hennekens and J.O. Taylor, Prevalence of Alzheimer's disease in a community population of older persons. Higher than previously reported, Jama 262 (1989), 2551-2556.

[29] A.J. Farrall and J.M. Wardlaw, Blood-brain barrier: Ageing and microvascular disease - systematic review and metaanalysis, Neurobiol Aging (2007)

[30] F. Foschi, J. Izard, H. Sasaki, V. Sambri, C. Prati, R. Muller and P. Stashenko, Treponema denticola in disseminating endodontic infections, J Dent Res 85 (2006), 761-765.

[31] J. Gamonal, A. Acevedo, A. Bascones, O. Jorge and A. Silva, Levels of interleukin-1 beta, -8 , and -10 and RANTES in gingival crevicular fluid and cell populations in adult periodontitis patients and the effect of periodontal treatment, $J$ Periodontol 71 (2000), 1535-1545.

[32] M. Gatz, C.A. Reynolds, L. Fratiglioni, B. Johansson, J.A. Mortimer, S. Berg, A. Fiske and N.L. Pedersen, Role of genes and environments for explaining Alzheimer disease, Arch Gen Psychiatry 63 (2006), 168-174.

[33] M.J. Gatz M, Fratiglioni L, Johansson B, Berg S, Reynolds CA, Pedersen NL, Potentially modifiable risk factors for dementia in identical twins, Alzheimers Dementia 2 (2006), $110-117$.

[34] F.C. Gibson, 3rd, C. Hong, H.H. Chou, H. Yumoto, J. Chen, E. Lien, J. Wong and C.A. Genco, Innate immune recognition of invasive bacteria accelerates atherosclerosis in apolipoprotein E-deficient mice, Circulation 109 (2004), 2801-2806.

[35] J. Gieffers, E. Reusche, W. Solbach and M. Maass, Failure to detect Chlamydia pneumoniae in brain sections of Alzheimer's disease patients, J Clin Microbiol 38 (2000), 881-882.

[36] J.P. Godbout, J. Chen, J. Abraham, A.F. Richwine, B.M. Berg, K.W. Kelley and R.W. Johnson, Exaggerated neuroin- flammation and sickness behavior in aged mice following activation of the peripheral innate immune system, FASEB 19 (2005), 1329-1331.

[37] W.S. Griffin, L. Liu, Y. Li, R.E. Mrak and S.W. Barger, Interleukin-1 mediates Alzheimer and Lewy body pathologies, J Neuroinflammation 3 (2006), 5.

[38] A.D. Haffajee and S.S. Socransky, Introduction to microbial aspects of periodontal biofilm communities, development and treatment, Periodontol 200042 (2006), 7-12.

[39] V.I. Haraszthy, J.J. Zambon, M. Trevisan, M. Zeid and R.J. Genco, Identification of periodontal pathogens in atheromatous plaques, J Periodontol 71 (2000), 1554-1560.

[40] G.J. Ho, R. Drego, E. Hakimian and E. Masliah, Mechanisms of cell signaling and inflammation in Alzheimer's disease, Curr Drug Targets Inflamm Allergy 4 (2005), 247-256.

[41] C. Holmes, M. El-Ok1, A.L. Williams, C. Cunningham, D. Wilcockson and V.H. Perry, Systemic infection, interleukin 1 beta, and cognitive decline in Alzheimer's disease, J Neurol Neurosurg Psychiatry 74 (2003), 788-789.

[42] P.P. Hujoel, G.C. Armitage and R.I. Garcia, A perspective on clinical significance, J Periodontol 71 (2000), 1515-1518.

[43] M. Ide, D. Jagdev, P.Y. Coward, M. Crook, G.R. Barclay and R.F. Wilson, The short-term effects of treatment of chronic periodontitis on circulating levels of endotoxin, C-reactive protein, tumor necrosis factor-alpha, and interleukin-6, $J \mathrm{Pe}$ riodontol 75 (2004), 420-428.

[44] B.A. in t' Veld, A. Ruitenberg, A. Hofman, L.J. Launer, C.M. van Duijn, T. Stijnen, M.M. Breteler and B.H. Stricker, Nonsteroidal antiinflammatory drugs and the risk of Alzheimer's disease, N Engl J Med 345 (2001), 1515-1521.

[45] R.F. Itzhaki, M.A. Wozniak, D.M. Appelt and B.J. Balin, Infiltration of the brain by pathogens causes Alzheimer's disease, Neurobiol Aging 25 (2004), 619-627.

[46] W.M. Jenkins and P.N. Papapanou, Epidemiology of periodontal disease in children and adolescents, Periodontol 2000 26 (2001), 16-32.

[47] R.B. Johnson, N. Wood and F.G. Serio, Interleukin-11 and IL17 and the pathogenesis of periodontal disease, J Periodontol 75 (2004), 37-43.

[48] J. Kalman, A. Juhasz, G. Laird, P. Dickens, T. Jardanhazy, A. Rimanoczy, I. Boncz, W.L. Parry-Jones and Z. Janka, Serum interleukin-6 levels correlate with the severity of dementia in Down syndrome and in Alzheimer's disease, Acta Neurol Scand 96 (1997), 236-240.

[49] T. Kawai, T. Matsuyama, Y. Hosokawa, S. Makihira, M. Seki, N.Y. Karimbux, R.B. Goncalves, P. Valverde, S. Dibart, Y.P. Li, L.A. Miranda, C.W. Ernst, Y. Izumi and M.A. Taubman, $\mathrm{B}$ and $\mathrm{T}$ lymphocytes are the primary sources of RANKL in the bone resorptive lesion of periodontal disease, Am J Pathol 169 (2006), 987-998.

[50] R. Kikkert, M.L. Laine, L.A. Aarden and A.J. van Winkelhoff, Activation of toll-like receptors 2 and 4 by gramnegative periodontal bacteria, Oral Microbiol Immunol 22 (2007), 145-151.

[51] J.M. Kim, R. Stewart, M. Prince, S.W. Kim, S.J. Yang, I.S. Shin and J.S. Yoon, Dental health, nutritional status and recent-onset dementia in a Korean community population, Int J Geriatr Psychiatry 22 (2007), 850-855.

[52] A. Klegeris, D.G. Walker and P.L. McGeer, Interaction of Alzheimer beta-amyloid peptide with the human monocytic cell line THP-1 results in a protein kinase C-dependent secretion of tumor necrosis factor-alpha, Brain Res 747 (1997), 114-121. 
[53] K. Kondo, M. Niino and K. Shido, A case-control study of Alzheimer's disease in Japan - significance of life-styles, Dementia 5 (1994), 314-326.

[54] J.P. Konsman, B. Drukarch and A.M. Van Dam, (Peri)vascular production and action of pro-inflammatory cytokines in brain pathology, Clin Sci (Lond) 112 (2007), 1-25.

[55] K.S. Kornman, R.C. Page and M.S. Tonetti, The host response to the microbial challenge in periodontitis: assembling the players, Periodontol 200014 (1997), 33-53.

[56] J. Kountouras, E. Gavalas, C. Zavos, C. Stergiopoulos, D. Chatzopoulos, N. Kapetanakis and D. Gisakis, Alzheimer's disease and Helicobacter pylori infection: Defective immune regulation and apoptosis as proposed common links, Med Hypotheses 68 (2007), 378-388.

[57] J.M. Kramer and S.L. Gaffen, Interleukin-17: a new paradigm in inflammation, autoimmunity, and therapy, $J P e$ riodontol 78 (2007), 1083-1093.

[58] H.K. Kuo, C.J. Yen, C.H. Chang, C.K. Kuo, J.H. Chen and F. Sorond, Relation of C-reactive protein to stroke, cognitive disorders, and depression in the general population: systematic review and meta-analysis, Lancet Neurol 4 (2005), 371-380.

[59] B. Kurtis, G. Tuter, M. Serdar, P. Akdemir, C. Uygur, E. Firatli and B. Bal, Gingival crevicular fluid levels of monocyte chemoattractant protein-1 and tumor necrosis factor-alpha in patients with chronic and aggressive periodontitis, J Periodontol 76 (2005), 1849-1855.

[60] A.J. Lerner, P. Hedera, E. Koss, J. Stuckey and R.P. Friedland, Delirium in Alzheimer disease, Alzheimer Dis Assoc Disord 11 (1997), 16-20.

[61] U.H. Lerner, Inflammation-induced bone remodeling in periodontal disease and the influence of post-menopausal osteoporosis, J Dent Res 85 (2006), 596-607.

[62] F. Licastro, M. Chiappelli, M. Ruscica, V. Carnelli and M.M. Corsi, Altered cytokine and acute phase response protein levels in the blood of children with Downs syndrome: relationship with dementia of Alzheimer's type, Int J Immunopathol Pharmacol 18 (2005), 165-172.

[63] J. Licinio and M.L. Wong, Pathways and mechanisms for cytokine signaling of the central nervous system, J Clin Invest 100 (1997), 2941-2947.

[64] B.G. Loos, J. Craandijk, F.J. Hoek, P.M. Wertheim-van Dillen and U. van der Velden, Elevation of systemic markers related to cardiovascular diseases in the peripheral blood of periodontitis patients, J Periodontol 71 (2000), 1528-1534.

[65] B.G. Loos, Systemic markers of inflammation in periodontitis, J Periodontol 76 (2005), 2106-2115.

[66] V. Lucas and G.J. Roberts, Odontogenic bacteremia following tooth cleaning procedures in children, Pediatr Dent 22 (2000), 96-100.

[67] L.F. Lue, R. Rydel, E.F. Brigham, L.B. Yang, H. Hampel, G.M. Murphy, Jr., L. Brachova, S.D. Yan, D.G. Walker, Y. Shen and J. Rogers, Inflammatory repertoire of Alzheimer's disease and nondemented elderly microglia in vitro, Glia $\mathbf{3 5}$ (2001), 72-79.

[68] A.B. MacDonald and J.M. Miranda, Concurrent neocortical borreliosis and Alzheimer's disease, Hum Pathol 18 (1987), 759-761.

[69] E.G. McGeer, K. Yasojima, C. Schwab and P.L. McGeer, The pentraxins: possible role in Alzheimer's disease and other innate inflammatory diseases, Neurobiol Aging 22 (2001), 843-848.

[70] P.L. McGeer and E.G. McGeer, Anti-inflammatory drugs in the fight against Alzheimer's disease, Ann N Y Acad Sci 777 (1996), 213-220.

[71] P.L. McGeer and E.G. McGeer, Inflammation, autotoxicity and Alzheimer disease, Neurobiol Aging 22 (2001), 799-809.

[72] P.L. McGeer and E.G. McGeer, Polymorphisms in inflammatory genes and the risk of Alzheimer disease, Arch Neurol 58 (2001), 1790-1792.

[73] P.L. McGeer and E.G. McGeer, Innate immunity, local inflammation, and degenerative disease, Sci Aging Knowledge Environ 2002 (2002), re3.

[74] P.L. McGeer, J. Rogers and E.G. McGeer, Inflammation, anti-inflammatory agents and Alzheimer disease: the last 12 years, J Alzheimers Dis 9 (2006), 271-276.

[75] L. Meda, M.A. Cassatella, G.I. Szendrei, L. Otvos, Jr., P. Baron, M. Villalba, D. Ferrari and F. Rossi, Activation of microglial cells by beta-amyloid protein and interferon-gamma, Nature 374 (1995), 647-650.

[76] L. Meda, P. Baron and G. Scarlato, Glial activation in Alzheimer's disease: the role of Abeta and its associated proteins, Neurobiol Aging 22 (2001), 885-893.

[77] M.A. Mendall, P. Patel, L. Ballam, D. Strachan and T.C. Northfield, $\mathrm{C}$ reactive protein and its relation to cardiovascular risk factors: a population based cross sectional study, Bmj 312 (1996), 1061-1065.

[78] J. Miklossy, Alzheimer's disease - a spirochetosis?, Neuroreport 4 (1993), 1069.

[79] J. Miklossy, S. Kasas, R.C. Janzer, F. Ardizzoni and H. Van der Loos, Further ultrastructural evidence that spirochaetes may play a role in the aetiology of Alzheimer's disease, Neuroreport 5 (1994), 1201-1204.

[80] J. Miklossy, K. Khalili, L. Gern, R.L. Ericson, P. Darekar, L. Bolle, J. Hurlimann and B.J. Paster, Borrelia burgdorferi persists in the brain in chronic lyme neuroborreliosis and may be associated with Alzheimer disease, J Alzheimers Dis 6 (2004), 639-649; discussion 673-681.

[81] J. Miklossy, A. Kis, A. Radenovic, L. Miller, L. Forro, R. Martins, K. Reiss, N. Darbinian, P. Darekar, L. Mihaly and K. Khalili, Beta-amyloid deposition and Alzheimer's type changes induced by Borrelia spirochetes, Neurobiol Aging 27 (2006), 228-236.

[82] A.J. Miller, G.N. Luheshi, N.J. Rothwell and S.J. Hopkins, Local cytokine induction by LPS in the rat air pouch and its relationship to the febrile response, Am J Physiol 272 (1997), R857-R861.

[83] L.E. Nee and C.F. Lippa, Alzheimer's disease in 22 twin pairs - 13-year follow-up: hormonal, infectious and traumatic factors, Dement Geriatr Cogn Disord 10 (1999), 148-151.

[84] L. Nibali, F. D'Aiuto, G. Griffiths, K. Patel, J. Suvan and M.S. Tonetti, Severe periodontitis is associated with systemic inflammation and a dysmetabolic status: a case-control study, J Clin Periodontol 34 (2007), 931-937.

[85] J.A. Nicoll, R.E. Mrak, D.I. Graham, J. Stewart, G. Wilcock, S. MacGowan, M.M. Esiri, L.S. Murray, D. Dewar, S. Love, T. Moss and W.S. Griffin, Association of interleukin-1 gene polymorphisms with Alzheimer's disease, Ann Neurol 47 (2000), 365-368.

[86] B. Noack, R.J. Genco, M. Trevisan, S. Grossi, J.J. Zambon and E. De Nardin, Periodontal infections contribute to elevated systemic C-reactive protein level, J Periodontol 72 (2001), 1221-1227.

[87] S. Offenbacher, V. Katz, G. Fertik, J. Collins, D. Boyd, G. Maynor, R. McKaig and J. Beck, Periodontal infection as a possible risk factor for preterm low birth weight, J Periodon- 
tol 67 (1996), 1103-1113.

[88] S. Offenbacher, E.L. Riche, S.P. Barros, Y.A. Bobetsis, D. Lin and J.D. Beck, Effects of maternal Campylobacter rectus infection on murine placenta, fetal and neonatal survival, and brain development, J Periodontol 76 (2005), 2133-2143.

[89] K. Okabe, K. Nakagawa and E. Yamamoto, Factors affecting the occurrence of bacteremia associated with tooth extraction, Int J Oral Maxillofac Surg 24 (1995), 239-242.

[90] K. Okuda, K. Ishihara, T. Nakagawa, A. Hirayama, Y. Inayama and K. Okuda, Detection of Treponema denticola in atherosclerotic lesions, J Clin Microbiol 39 (2001), 11141117.

[91] B.J. Paster, I. Olsen, J.A. Aas and F.E. Dewhirst, The breadth of bacterial diversity in the human periodontal pocket and other oral sites, Periodontol 200042 (2006), 80-87.

[92] T.A. Pearson, T.L. Bazzarre, S.R. Daniels, J.M. Fair, S.P. Fortmann, B.A. Franklin, L.B. Goldstein, Y. Hong, G.A. Mensah, J.F. Sallis, Jr., S. Smith, Jr., N.J. Stone and K.A. Taubert, American Heart Association guide for improving cardiovascular health at the community level: a statement for public health practitioners, healthcare providers, and health policy makers from the American Heart Association Expert Panel on Population and Prevention Science, Circulation 107 (2003), 645-651.

[93] V.H. Perry, T.A. Newman and C. Cunningham, The impact of systemic infection on the progression of neurodegenerative disease, Nat Rev Neurosci 4 (2003), 103-112.

[94] H.G. Prigerson, Costs to society of family caregiving for patients with end-stage Alzheimer's disease, $N$ Engl J Med 349 (2003), 1891-1892.

[95] A. Pucar, J. Milasin, V. Lekovic, M. Vukadinovic, M. Ristic, S. Putnik and E.B. Kenney, Correlation between atherosclerosis and periodontal putative pathogenic bacterial infections in coronary and internal mammary arteries, J Periodontol 78 (2007), 677-682.

[96] P.J. Pussinen, T. Vilkuna-Rautiainen, G. Alfthan, K. Mattila and S. Asikainen, Multiserotype enzyme-linked immunosorbent assay as a diagnostic aid for periodontitis in large-scale studies, J Clin Microbiol 40 (2002), 512-518.

[97] N. Quan and W.A. Banks, Brain-immune communication pathways, Brain Behav Immun 21 (2007), 727-735.

[98] M. Quirynen, C. Mongardini, M. de Soete, M. Pauwels, W. Coucke, J. van Eldere and D. van Steenberghe, The role of chlorhexidine in the one-stage full-mouth disinfection treatment of patients with advanced adult periodontitis. Longterm clinical and microbiological observations, J Clin Periodontol 27 (2000), 578-589.

[99] S. Ray, M. Britschgi, C. Herbert, Y. Takeda-Uchimura, A. Boxer, K. Blennow, L.F. Friedman, D.R. Galasko, M. Jutel, A. Karydas, J.A. Kaye, J. Leszek, B.L. Miller, L. Minthon, J.F. Quinn, G.D. Rabinovici, W.H. Robinson, M.N. Sabbagh, Y.T. So, D.L. Sparks, M. Tabaton, J. Tinklenberg, J.A. Yesavage, R. Tibshirani and T. Wyss-Coray, Classification and prediction of clinical Alzheimer's diagnosis based on plasma signaling proteins, Nat Med 13 (2007), 1359-1362.

[100] S. Rivest, Molecular insights on the cerebral innate immune system, Brain Behav Immun 17 (2003), 13-19.

[101] G.R. Riviere, K.H. Riviere and K.S. Smith, Molecular and immunological evidence of oral Treponema in the human brain and their association with Alzheimer's disease, Oral Microbiol Immunol 17 (2002), 113-118.

[102] G. Roberts, Dentists are innocent! "Everyday" bacteremia is the real culprit: a review and assessment of the evidence that dental surgical procedures are a principal cause of bacterial endocarditis in children., Pediatr Cardiol. 20 (1999), 317325.

[103] H.E. Romeo, D.L. Tio, S.U. Rahman, F. Chiappelli and A.N. Taylor, The glossopharyngeal nerve as a novel pathway in immune-to-brain communication: relevance to neuroimmune surveillance of the oral cavity, J Neuroimmunol 115 (2001), 91-100.

[104] F.R. Saglie, F.A. Carranza Jr., M.G. Newman, L. Cheng and K.J. Lewin, Identification of tissue-invading bacteria in human periodontal disease, J Periodontal Res 17 (1982), 452455.

[105] F.A. Scannapieco and M.P. Rethman, The relationship between periodontal diseases and respiratory diseases, Dent Today 22 (2003), 79-83.

[106] J.C. Schiltz and P.E. Sawchenko, Signaling the brain in systemic inflammation: the role of perivascular cells, Front Biosci 8 (2003), s1321-s1329.

[107] R. Schmidt, H. Schmidt, J.D. Curb, K. Masaki, L.R. White and L.J. Launer, Early inflammation and dementia: a 25-year follow-up of the Honolulu-Asia Aging Study, Ann Neurol 52 (2002), 168-174.

[108] L. Shapira, S. Takashiba, S. Amar and T.E. Van Dyke, Porphyromonas gingivalis lipopolysaccharide stimulation of human monocytes: dependence on serum and CD14 receptor, Oral Microbiol Immunol 9 (1994), 112-117.

[109] L. Shapira, S. Ayalon and T. Brenner, Effects of Porphyromonas gingivalis on the central nervous system: activation of glial cells and exacerbation of experimental autoimmune encephalomyelitis, J Periodontol 73 (2002), 511-516.

[110] J. Sheldon, Laboratory testing in autoimmune rheumatic diseases, Best Pract Res Clin Rheumatol 18 (2004), 249-269.

[111] J.G. Sheng, S.H. Bora, G. Xu, D.R. Borchelt, D.L. Price and V.E. Koliatsos, Lipopolysaccharide-inducedneuroinflammation increases intracellular accumulation of amyloid precursor protein and amyloid beta peptide in APPswe transgenic mice, Neurobiol Dis 14 (2003), 133-145.

[112] T.A. Silva, G.P. Garlet, S.Y. Fukada, J.S. Silva and F.Q. Cunha, Chemokines in oral inflammatory diseases: apical periodontitis and periodontal disease, J Dent Res 86 (2007), 306-319.

[113] G.D. Slade, S. Offenbacher, J.D. Beck, G. Heiss and J.S. Pankow, Acute-phase inflammatory response to periodontal disease in the US population, J Dent Res 79 (2000), 49-57.

[114] J. Slots, Herpesviral-bacterial synergy in the pathogenesis of human periodontitis, Curr Opin Infect Dis 20 (2007), 278283.

[115] S.S. Socransky and A.D. Haffajee, The nature of periodontal diseases, Ann Periodontol 2 (1997), 3-10.

[116] S.S. Socransky, A.D. Haffajee, M.A. Cugini, C. Smith and R.L. Kent, Jr., Microbial complexes in subgingival plaque, $J$ Clin Periodontol 25 (1998), 134-144.

[117] S.S. Socransky and A.D. Haffajee, Dental biofilms: difficult therapeutic targets, Periodontol 200028 (2002), 12-55.

[118] P.S. Stein, M. Desrosiers, S.J. Donegan, J.F. Yepes and R.J. Kryscio, Tooth loss, dementia and neuropathology in the Nun Study, J Am Dent Assoc 138 (2007), 1314-1322.

[119] R. Stewart and V. Hirani, Dental health and cognitive impairment in an English national survey population, $J$ Am Geriatr Soc 55 (2007), 1410-1414.

[120] W.F. Stewart, C. Kawas, M. Corrada and E.J. Metter, Risk of Alzheimer's disease and duration of NSAID use, Neurology 48 (1997), 626-632.

[121] C.A. Szekely, J.C. Breitner, A.L. Fitzpatrick, T.D. Rea, B.M. Psaty, L.H. Kuller and P.P. Zandi, NSAID use and dementia 
risk in the Cardiovascular Health Study. Role of APOE and NSAID type, Neurology 70 (2008), 17-24.

[122] C.A. Szekely, T. Town and P.P. Zandi, NSAIDs for the chemoprevention of Alzheimer's disease, Subcell Biochem 42 (2007), 229-248.

[123] Z.S. Tan, A.S. Beiser, R.S. Vasan, R. Roubenoff, C.A. Dinarello, T.B. Harris, E.J. Benjamin, R. Au, D.P. Kiel, P.A. Wolf and S. Seshadri, Inflammatory markers and the risk of Alzheimer disease: the Framingham Study, Neurology 68 (2007), 1902-1908.

[124] C.E. Teunissen, M.P. van Boxtel, H. Bosma, E. Bosmans, J. Delanghe, C. De Bruijn, A. Wauters, M. Maes, J. Jolles, H.W Steinbusch and J. de Vente, Inflammation markers in relation to cognition in a healthy aging population, $J$ Neuroimmunol 134 (2003), 142-150.

[125] R.S. Tilvis, M.H. Kahonen-Vare, J. Jolkkonen, J. Valvanne, K.H. Pitkala and T.E. Strandberg, Predictors of cognitive decline and mortality of aged people over a 10 -year period, J Gerontol A Biol Sci Med Sci 59 (2004), 268-274.

[126] M.S. Tonetti, F. D’Aiuto, L. Nibali, A. Donald, C. Storry, M. Parkar, J. Suvan, A.D. Hingorani, P. Vallance and J. Deanfield, Treatment of periodontitis and endothelial function, $N$ Engl J Med 356 (2007), 911-920.

[127] D. Tousoulis, C. Antoniades and C. Stefanadis, Assessing inflammatory status in cardiovascular disease, Heart 93 (2007), 1001-1007.

[128] K.P. Townsend and D. Pratico, Novel therapeutic opportunities for Alzheimer's disease: focus on nonsteroidal antiinflammatory drugs, FASEB 19 (2005), 1592-1601.

[129] V.J. Uitto, Gingival crevice fluid - an introduction, Periodontol 200031 (2003), 9-11.

[130] L.R. Watkins, L.E. Goehler, J.K. Relton, N. Tartaglia, L. Silbert, D. Martin and S.F. Maier, Blockade of interleukin1 induced hyperthermia by subdiaphragmatic vagotomy: evidence for vagal mediation of immune-brain communication, Neurosci Lett 183 (1995), 27-31.

[131] S. Weggen, J.L. Eriksen, S.A. Sagi, C.U. Pietrzik, V. Ozols, A. Fauq, T.E. Golde and E.H. Koo, Evidence that nonsteroidal anti-inflammatory drugs decrease amyloid beta 42 production by direct modulation of gamma-secretase activity, J Biol Chem 278 (2003), 31831-31837.

[132] M.A. Wozniak, S.J. Shipley, C.B. Dobson, S.P. Parker, F.T. Scott, M. Leedham-Green, J. Breuer and R.F. Itzhaki, Does apolipoprotein $\mathrm{E}$ determine outcome of infection by varicella zoster virus and by Epstein Barr virus? Eur J Hum Genet 15 (2007), 672-678.

[133] K. Yaffe, K. Lindquist, B.W. Penninx, E.M. Simonsick, M. Pahor, S. Kritchevsky, L. Launer, L. Kuller, S. Rubin and T. Harris, Inflammatory markers and cognition in wellfunctioning African-American and white elders, Neurology 61 (2003), 76-80.

[134] K. Yasojima, C. Schwab, E.G. McGeer and P.L. McGeer, Human neurons generate C-reactive protein and amyloid P: upregulation in Alzheimer's disease, Brain Res 887 (2000), $80-89$.

[135] Y. Zhong, G.D. Slade, J.D. Beck and S. Offenbacher, Gingival crevicular fluid interleukin-1beta, prostaglandin E2 and periodontal status in a community population, J Clin Periodontol 34 (2007), 285-293.

[136] S.G. Zhu, J.G. Sheng, R.A. Jones, M.M. Brewer, X.Q. Zhou, R.E. Mrak and W.S. Griffin, Increased interleukin-1beta converting enzyme expression and activity in Alzheimer disease, J Neuropathol Exp Neurol 58 (1999), 582-587.

[137] E.E. Zijlstra, G.R. Swart, F.J. Godfroy and J.E. Degener, Pericarditis, pneumonia and brain abscess due to a combined Actinomyces-Actinobacillus actinomycetemcomitans infection, J Infect 25 (1992), 83-87. 